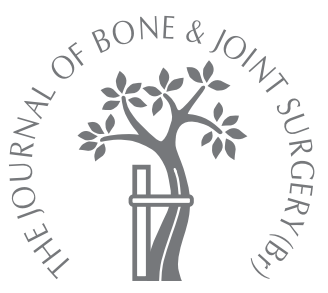

V. Musahl,

I. Tarkin,

P. Kobbe,

C. Tzioupis,

P. A. Siska,

H.-C. Pape

From the University

of Pittsburgh,

Pittsburgh, USA

V. Musahl, MD, Resident

II. Tarkin, MD, Assistant

Professor

I. Kobbe, MD, Research

Fellow

= C. Tzioupis, MD, Research

Fellow

P. A. Siska, MD, Clinical

Instructor

Department of Orthopaedic

Surgery, University of

Pittsburgh, Kaufmann Medical

Building, Suite 1010, 3471 Fifth

Avenue, Pittsburgh

Pennsylvania 15213, USA

H.-C. Pape, MD, FACS,

W. Pauwels Professor

Chairman,

Department of Orthopaedics

and Trauma Surgery,

Pauwelsstrasse 30,52057

Aachen, Germany.

Correspondence should be sent to Professor H.-C. Pape; e-mail: papehc@aol.com

(C)2009 British Editorial Society of Bone and Joint Surgery doi:10.1302/0301-620X.91B4. $20966 \$ 2.00$

$J$ Bone Joint Surg [Br] 2009:91-B:426-33.

口 REVIEW ARTICLE

\title{
New trends and techniques in open reduction and internal fixation of fractures of the tibial plateau
}

\begin{abstract}
The operative treatment of displaced fractures of the tibial plateau is challenging. Recent developments in the techniques of internal fixation, including the development of locked plating and minimal invasive techniques have changed the treatment of these fractures. We review current surgical approaches and techniques, improved devices for internal fixation and the clinical outcome after utilisation of new methods for locked plating.
\end{abstract}

In the treatment of fractures of the tibial plateau emphasis has been placed on the strict adherence to the principles of anatomical reduction, rigid fixation and early movement. ${ }^{1}$ At operation direct reduction requires periosteal stripping and stable internal fixation necessitates considerable dissection, thereby sacrificing the vascular supply. These techniques are associated with high rates of complication, with nonunion, the frequent requirement for secondary bone grafts and loss of reduction being of particular concern. ${ }^{2-4}$

The development of locking implants has allowed the use of minimally invasive approaches often allowing unilateral plating ${ }^{5-7}$ with improvement in the handling of soft tissue. ${ }^{8-11}$ The success of spanning external fixation ${ }^{12,13}$ in pilon fractures ${ }^{14}$ has resulted in this method being used for fractures of the tibial plateau. This review discusses the surgical principles and approaches in the light of current techniques.

\section{Radiological assessment of fractures}

Standard pre-operative evaluation has included anteroposterior (AP) lateral and oblique radiographs. Additional traction views or tomograms may be obtained to facilitate the assessment of depression, true condylar widening and comminution. The use of threedimensional (3D) reconstruction CT and intraoperative CT has been shown to be superior to fluoroscopy for assessing reduction of the fracture $^{15-20}$ (Fig. 1).

MRI in the pre-operative assessment is usually confined to the soft-tissue structures, and may be used to evaluate injury to the menisci and collateral ligaments. As a research tool MRI has advanced our knowledge of concomitant injuries. Mui et a $\mathrm{l}^{18}$ compared the use of CT and MRI and showed that although ligament injuries can be safely ruled out by CT, MRI is required to assess meniscal damage. Lowenergy fractures of Schatzker type-II were identified as those most commonly associated with concomitant soft-tissue injuries. Gardner et $\mathrm{al}^{21}$ reviewed 103 patients with mainly low-energy fractures and found injuries to the lateral meniscus in $90 \%$. However, this figure does not represent the incidence in high-energy fractures, and it should be remembered that all meniscal tears do not need surgical fixation. The value of MRI in diagnosing meniscal injuries has been shown to increase interobserver agreement on the classification and operative management of these fractures. ${ }^{22}$ The medial meniscus is most commonly injured in fractures of the medial plateau. Rupture of the cruciate ligaments occurs commonly as a concomitant injury in bicondylar fractures of the plateau. Overall, the anterior cruciate ligament (ACL) is injured in $57 \%$ and the posterior cruciate ligament (PCL) in $28 \%$ of these cases.21,22 Injuries to the collateral ligaments can occur with all types of plateau fractures. The lateral is most commonly injured in medial and bicondylar plateau fractures $(57 \%)$ and the medial in lateral and bicondylar fractures (36\%).21,22 Anteromedial compression fractures indicate injury to the posterolateral structures and the PCL. In a study by Chiba et al, ${ }^{23}$ all 12 patients who presented with anteromedial compression fractures had associated lateral or posterolateral laxity.

\section{Shortcomings of classification systems} All classification systems have shortcomings in terms of interobserver reliability and are not comprehensive. ${ }^{24,25}$ In particular, there is still a 


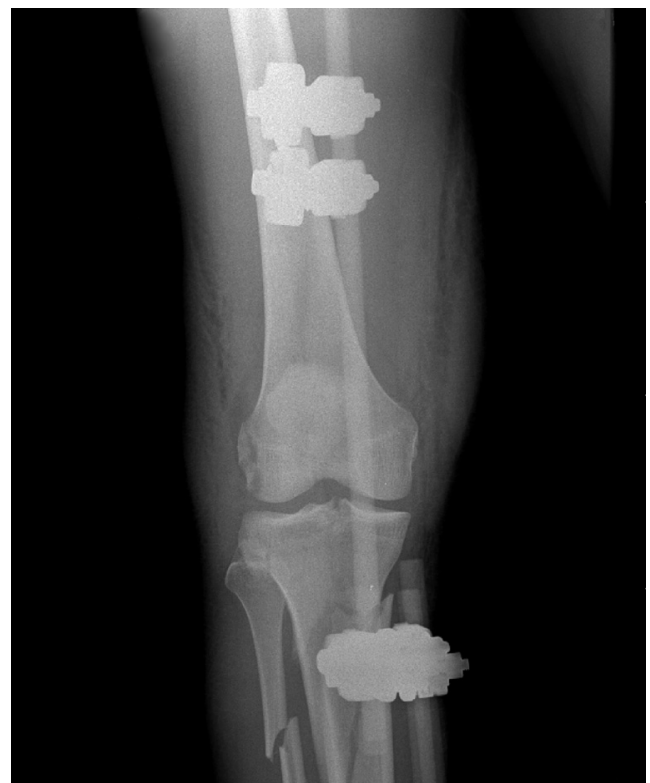

Fig. 1a

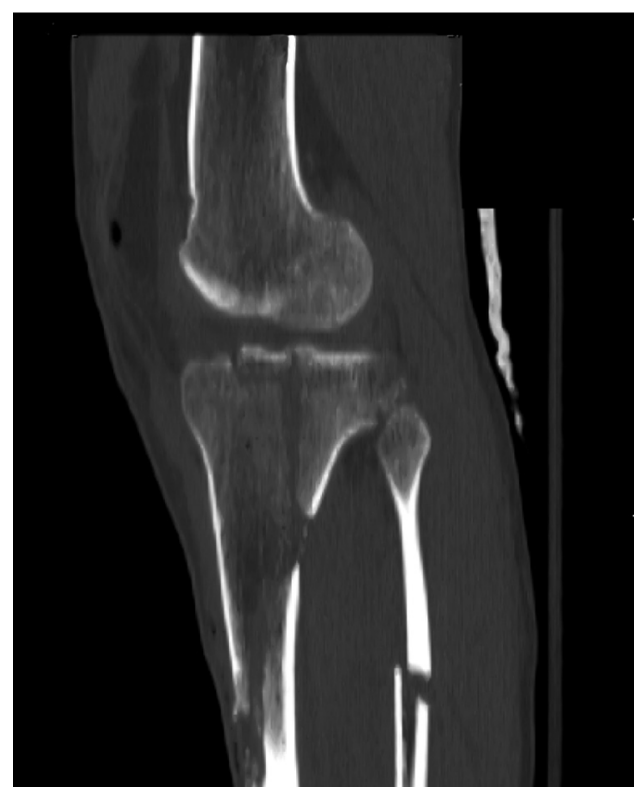

Fig. 1b

a) Anteroposterior radiograph of a high-energy bicondylar fracture of the tibial plateau after spanning external fixation, b) sagittal CT in traction.

lack of prediction of the outcome and in the need for a second approach or bone graft. The posterior shear fracture is not included in these classifications. Barei et $\mathrm{al}^{26}$ proposed a rank-order system to classify fractures of the tibial plateau which allowed for planning of the surgical strategy. The fracture morphology as described by the AO/OTA classification, 1 appears to be a particularly useful tool for the purpose of research and communication. ${ }^{3,27}$

The Schatzker classification3 distinguishes between fractures of the lateral and medial plateau and separates simple from complex patterns of injury. Isolated depression fractures (type III) are exceedingly rare. ${ }^{21} \mathrm{~A}$ type- $\mathrm{V}$ fracture is a bicondylar injury with the interspinous region remaining in continuity with the diaphysis of the tibia. Routine use of CT has improved the accuracy of describing patterns of fracture and has shown that in most cases there are visible fracture lines which separate the interspinous region from the diaphysis. The posterior shear fracture is extremely unstable, associated with severe concomitant injuries, and requires specific approaches. ${ }^{28,29}$

Oblique posteromedial fractures, classified as AO/OTA B1.3 and B3.3, were reviewed by Wahlquist et al. ${ }^{24}$ They proposed a simple classification into type-A, $-B$, and -C fractures. Type-A fractures are medial to, type-B fractures are through, and type-C fractures lateral to the intercondylar spines. A high incidence of associated injuries was found with type-C fractures including compartment syndrome and neurological and vascular complications. These unstable fractures must be evaluated carefully since they can be associated with complications similar to those seen in dislocations of the knee. With displaced oblique posteromedial fractures, careful assessment of the vascular status and angiography may be required to rule out neurovascular compromise.

\section{The value of the single-incision and minimally invasive percutaneous plate osteosynthesis (MIPPO) techniques}

The single-incision anterolateral approach is commonly used for simple split and split-depression fractures confined to the lateral plateau. In preparation for surgery, the leg is best placed in $30^{\circ}$ of flexion to release the collateral ligamentous structures. A straight incision is performed from the anterolateral joint line to $6 \mathrm{~cm}$ to $8 \mathrm{~cm}$ distally to allow a later approach for possible arthroplasty. In bicondylar injuries, the value of an additional medial buttress plate may be considered. Although type-C1 and type- $\mathrm{C} 2$ fractures are usually stable, in the case of displacement or severe comminution a medial plate may be helpful to maintain reduction. MIPPO has been advocated for both lowenergy and high-energy fractures. ${ }^{7,8,13,30,31}$

In a study of 69 high-energy fractures of the tibial plateau treated by unilateral locked plating by Gosling et $\mathrm{al}^{7}$ only one deep infection was observed, which the authors considered to be a result of sparing the patient a second incision. However, despite the use of a locking technique, loss of reduction was seen in $13 \%$ of the fractures. When dual-incision approaches are used a significantly higher rate of complications such as deep infection, arthrofibrosis and post-traumatic arthritis has been observed. ${ }^{2,26,32,33}$ 


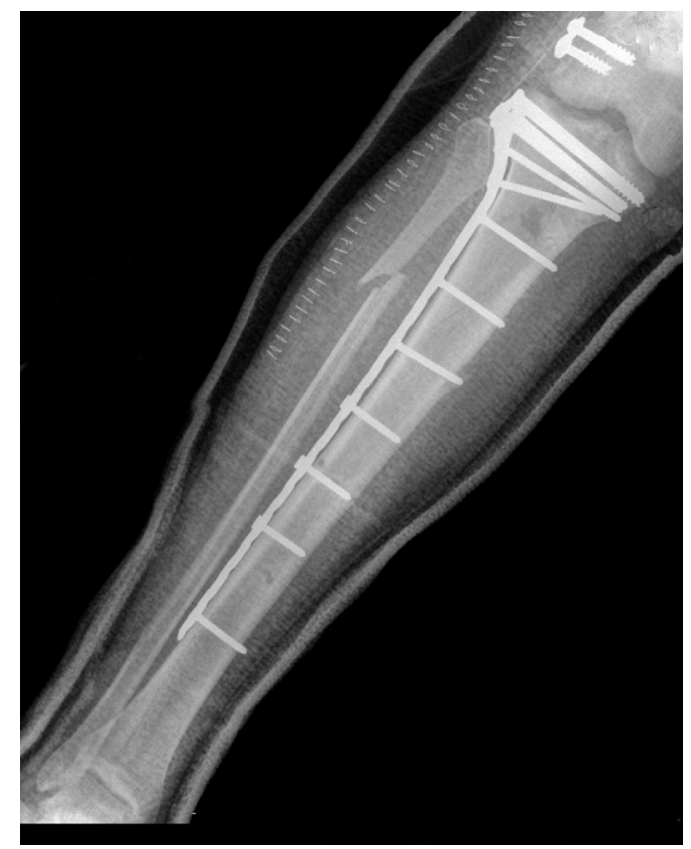

Fig. 2a

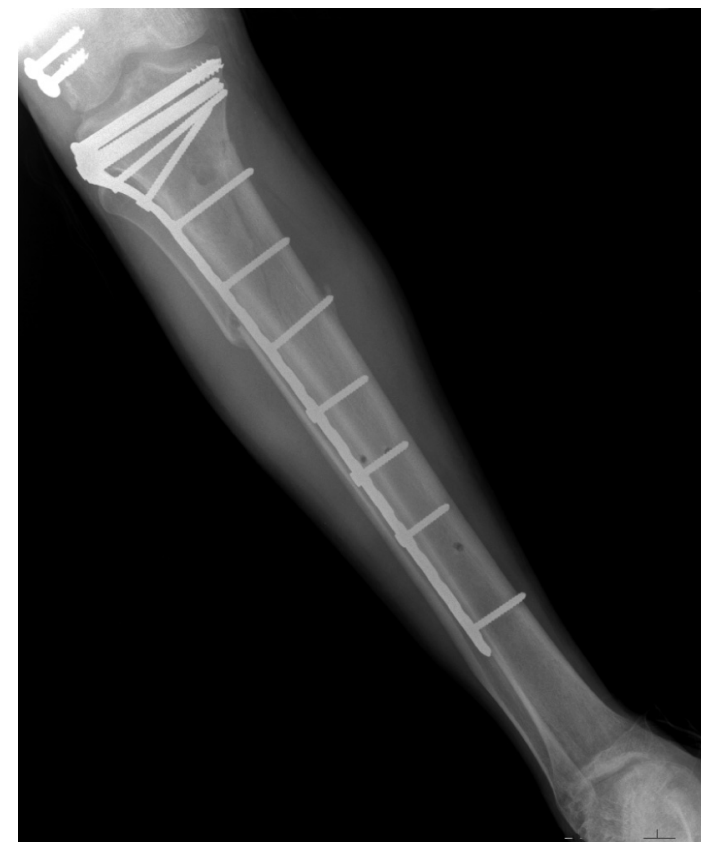

Fig. $2 b$

Anteroposterior radiographs of the same patient as in Figure 1 a) immediately after operation and b) at follow-up at four months.

The anterolateralapproach is usually performed first to expose and reduce the proximal aspect of the lateral condyle and secure intercondylar reduction. For fixation of the condyles to the shaft, lateral locking plates can then be slid submuscularly and extraperiosteally, bridging the metaphysis (Figs 2 and 3). If the condylar fragments are not comminuted and are well reduced the medial condyle can be controlled by a laterally-based locking plate alone. ${ }^{7,13,34}$ This is only possible if anatomical cortical contact between the fragments is present. It is therefore important for the surgeon to recognise intra-operatively whether cortical contact will be sufficient to spare a second approach. The additional small medial approach involves application of a medial antiglide plate or a small locking plate. The anterolateral incision is the standard approach for fractures of the tibial plateau but is very close to subsequent incisions which may be required for future arthroplasty procedures. In order to allow for this a midline incision may be used which also allows good access to the medial and lateral compartments. For certain fractures, especially those with posterior displacement, dual or posterior incisions may be required.

\section{Special situations requiring complex approaches}

Fibular osteotomy may be required in the presence of depression of the posterolateral plateau and posterolateral fracture dislocations. Despite the extensive dissection required, good clinical outcomes have been documented. 28,35

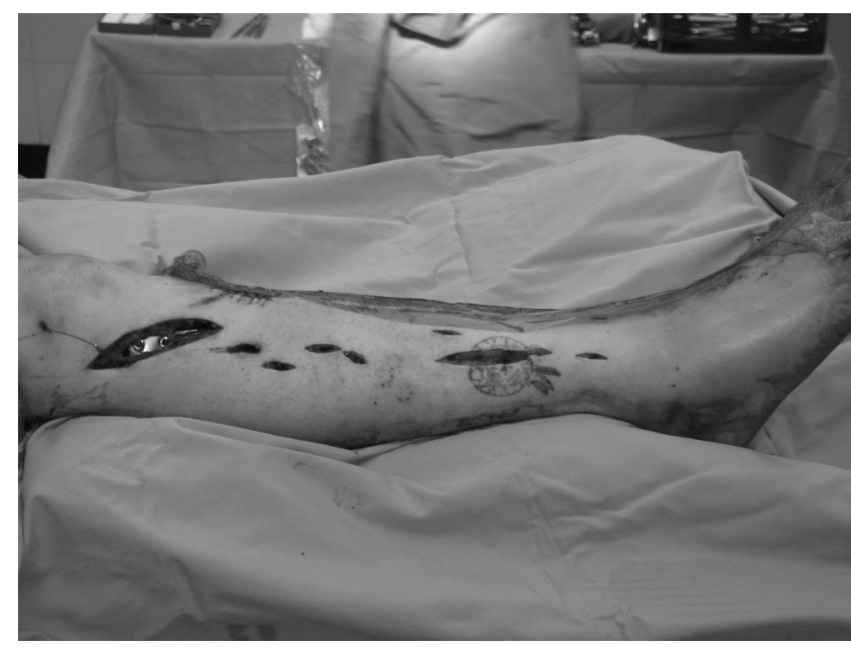

Fig. 3

Clinical photograph showing intra-operative application of a lateral locking plate using the minimally invasive percutaneous plate osteosynthesis.

Posteromedial plateau fractures, medial fracture dislocations and wedge-like posterior metaphyseal fractures are best managed from a posteromedial approach. ${ }^{36-38}$

The straight posterior approach is rarely indicated, but works well for isolated posterior shear fractures, injuries with avulsion of the PCL and posterior fracture dislocations. Bhattacharyya et $\mathrm{al}^{29}$ used this approach to treat 
31 posterior shear fractures. The use of buttress plates has been shown to give a good clinical outcome when accurate reduction has been achieved. ${ }^{29,39}$ The use of subchondral lag screws and buttress plates may be necessary to maintain anatomical reduction and T-plates or distal radial locking plates may be used.

High-energy bicondylar fractures, coronal split fractures of the posteromedial plateau, fractures with considerable medial comminution, posterior subluxation or fracture dislocation of the medial condyle and combined posteromedial and posterolateral fractures often require combined approaches. In these cases, the fractures are insufficiently stabilised by a laterally-based plate alone and usually require additional fixation to prevent varus malunion, despite the use of locking techniques.

\section{When are locking plates unnecessary?}

Conventional, non-locking plates which exert direct compression at the site of the fracture, are suitable for simple fracture patterns with minimal comminution. The development of atraumatic techniques of open reduction and stable internal fixation (ORIF) using slim, anatomically-configured implants has facilitated care of the soft tissues and allows early movement after fixation of the fracture. ${ }^{3,40-42}$ Fixation of non-comminuted single-split lateral plateau injuries may be accomplished by two or three 6.5 or 7.0 $\mathrm{mm}$ cannulated lag screws over guide-wires through small stab incisions. Biomechanical studies ${ }^{43-45}$ have shown the superiority of two lag screws over three or over a solitary antiglide plate. However, if the lateral fragment is exceptionally large or comminuted at its metaphyseal base, or if there is considerable osteoporosis, a laterally-based buttress plate or antiglide plate should be used..$^{43-45}$

For split-depressed lateral plateau fractures, the depressed articular segment is elevated and fixation of the condyle is achieved by the use of a buttress plate or peri-articular raft plate. If there is little comminution and good bone stock in selected cases it may be possible to use solitary lag screws without a plate. However, it is usually safer to apply an additional buttress plate through a small incision. Fractures of the medial plateau which present with little or no comminution are best treated by reduction through a small incision which may be sufficient to allow for screw fixation and additional buttress plating. Reduction can be achieved by a valgus stress because of the intact capsular attachments and maintained by percutaneously applied reduction forceps and multiple cannulated screws. In order to avoid shear forces, a buttress plate is recommended in addition to the compression achieved by lag screws. For high-energy fractures of the medial plateau with gross instability, comminution extending into the intercondylar eminence and injury to the lateral ligaments, open reduction and buttress plating are always required.

\section{When are locking plates indicated?}

Locked plates are indicated for high-energy fractures, those with severe comminution and in osteoporotic injuries.
Historically, fractures of the tibial plateau involving both condyles have required extensile exposures, dual plating and large-fragment implants, which have led to wound dehiscence, infection, articular collapse, nonunion and malalignment. In order to minimise soft-tissue injury, percutaneous techniques such as the use of femoral distractors, Kirschner (K-)wire joysticks and percutaneously applied reduction forceps is indicated to manipulate the major condylar fragments.

Laterally-based locking plates provide increased stability in the presence of metaphyseal or metadiaphyseal comminution, and may offer an alternative to an additional medial plate or external fixator for added support of the medial column when a non-locking plate is used for bicondylar fractures. ${ }^{8,46}$ This allows fixation through a single lateral incision, potentially avoiding wound dehiscence and infection associated with combined or extended approaches in which a medial buttress plate is used. ${ }^{2,47-49}$ Because interfragmentary compression cannot be achieved by locked plates, the supplementary use of interfragmentary screws may be required to prevent loss of reduction and to ensure adequate compression of the fragments. Biomechanical studies have shown the superiority of locked plates in these highenergy and osteoporotic fractures and have also compared locked plates with bicolumnar plating. ${ }^{50-52}$

Clinical outcome studies have reviewed the results of lateral locked plating for bicondylar fractures of the tibial plateau. ${ }^{7,8,30}$ Cole et al $^{8}$ described a prospective, clinical trial utilising the Less Invasive Stabilization System (LISS) in 54 proximal tibial fractures, of which $13 \%$ were associated with an ipsilateral fracture of the shaft, $13 \%$ were classified as AO/OTA type 41-C3 with extensive articular comminution and $31 \%$ were open. They observed malreduction in two patients with articular step-offs of $2 \mathrm{~mm}$ and $3 \mathrm{~mm}$, an apex anterior deformity of between $5^{\circ}$ and $10^{\circ}$ in four and a varus malreduction in another. There were no additional varus or valgus malreductions of more than $5^{\circ}$ and there was no late varus collapse or cut-out at the final follow-up. Union was achieved in $96 \%$ of patients with a rate of infection of $3.7 \%$.

Higher rates of malalignment of the proximal tibia have been reported when using the LISS system. ${ }^{30}$ A recent biomechanical study showed that dual-plate fixation allowed significantly less subsidence than isolated lateral locked plates after cyclical loading in a cadaver model. ${ }^{53}$ These studies suggest that while isolated lateral locked plating may offer a more biological approach to bicondylar fractures, and may provide a viable alternative for open fractures with a medial wound or fractures with tenuous soft tissues, classical dual plating remains the most rigid construct. The surgeon must assess which fixation is best suited for the pattern of bony and soft-tissue injury and the overall medical condition of the patient.

\section{Arthroscopy and fluoroscopy}

Arthroscopic-assisted reduction and internal fixation is recommended for certain types of plateau fractures. Pure 
depression fractures seem to be the most suitable, although they are rare. Extravasation of irrigation fluid, especially in extracapsular fractures, carries the risk of a compartment syndrome and must be used with extreme caution. ${ }^{54-56}$ Lobenhoffer et $\mathrm{al}^{57}$ have shown in a series of 168 patients that adequate reduction could be achieved by the use of either arthroscopy or fluoroscopy.

\section{Indirect fixation: the Ilizarov technique}

The Ilizarov circular ring fixator can be a valuable option for high-energy fractures with gross intra-articular comminution (AO/OTA type C3), especially when associated with severe soft-tissue compromise. Indirect reduction is achieved through ligamentotaxis by spanning the knee with a ring and two K-wires each in the distal femur and distal tibia. In order to avoid the occurrence of septic arthritis, the most proximal pins in the tibia must remain at least $14 \mathrm{~mm}$ distal to the joint line to prevent violation of the capsule of the knee. ${ }^{58}$ After anatomical alignment of the leg has been achieved, the articular surface can be reconstructed using indirect reduction and percutaneous fixation, either by Kwires, olive wires which allow compression or lag screws. The comminuted metaphyseal region is thereby bridged and remains in situ. Clinical studies ${ }^{59-63}$ have shown similar outcomes for ORIF and indirect reduction by wire fixation. The advantages of thin wire fixators are lower rates of reoperation, a shorter hospital stay and fewer complications both in number and severity. The rates of union are comparable, but loss of movement is common and must be carefully monitored post-operatively. There is a low threshold for manipulation under anaesthesia. ${ }^{64-66}$

\section{Clinical outcome}

It is difficult to determine the clinical outcome in these diverse injuries. Clinical studies must be defined by the pattern of fracture, the number and localisation of incisions performed, and the duration of follow-up, as summarised in Table I. ${ }^{7,13,16,26,28,29,43,67}$

The quality of articular reduction, the time to follow-up and the pattern of fracture play a major role in determining the outcome.

Articular reduction. Historically, the quality of articular congruency achieved after operation did not appear to be a paramount goal. In 1971, Lucht and Pilgaard ${ }^{68}$ stated that a good outcome occurred in $78 \%$ of their patients even if articular depression was up to $10 \mathrm{~mm}$. Later, Rasmussen ${ }^{69}$ noted a worse outcome when residual articular depression of $>5 \mathrm{~mm}$ was present. However, these studies had limited access to assessment of the fracture by CT. Subsequently, it became very evident that an anatomical reduction of the articular surface was mandatory to give a good outcome. ${ }^{67,70}$ In 41 patients with OTA type-C3 bicondylar fractures of the tibial plateau assessed five years after bicolumnar fixation, only $55 \%$ had been reduced to less than $2 \mathrm{~mm}$ of articular step-off. ${ }^{26}$ Considerable residual dysfunction was found in those patients with an anatomical reduction with more deformity than this. ${ }^{26}$
Time to follow-up. Keating et al, ${ }^{71}$ evaluated 25 split depression fractures, 22 pure depression fractures and two bicondylar fractures, finding that $95 \%$ had good or excellent results at one year. Egol et $\mathrm{al}^{13}$ found a rate of arthritic changes of $5 \%$ at a follow-up of 16 months. The multicentre, prospective, randomised clinical trial by the Canadian Orthopaedic Trauma Society showed that in patients followed for more than two years, $37 \%$ developed signs of osteoarthritis. ${ }^{60}$ In Marti et al's, ${ }^{67}$ study, with a follow-up of 168 weeks, $10 \%$ of patients had evidence of osteoarthritic changes. Thus, it appears that cartilage damage in displaced fractures may not be evident in the first year, but clinical signs of arthritis develop thereafter. However, the pattern of the fracture plays a major role.

Some authors have suggested that filling of the osseous defects may be important. Keating et $\mathrm{al}^{71}$ demonstrated that calcium phosphate was appropriate for this purpose. Others have indicated that autologous bone may be used although donor-site morbidity may be of concern. ${ }^{72,73}$ The use of allograft, hydroxyapatite grafts, or calcium-phosphate cement may also produce comparable results, but a definitive answer to this question is not available at present. ${ }^{72,73}$

Fracture pattern/approaches/clinical outcome measures. It would seem logical to expect a more limited outcome in very displaced and comminuted patterns of fracture. However, a study which compares the outcomes after different patterns is not yet available. The types of approach may also be an indicator of the severity of the fracture. Table I shows that assessment of follow-up and radiological and clinical outcome vary widely in the available literature and therefore comparisons of different studies are difficult.

The long-term outcome after fractures of the tibial plateau is limited. A favourable result seems to be achievable for low-energy injuries. ${ }^{57,74}$ Preservation of the meniscus and its ability to bear the load of the lateral compartment are important prognostic factors. ${ }^{75,76}$ In patients with highenergy fractures, the prognosis is best if mild-to-moderate articular displacement is present at the time of injury and articular reduction is achieved. . $^{73,26,64,66}$

\section{Complications}

These are more likely to result from high-energy than from low-energy fractures. The outcome and complications are difficult to interpret since reports are often based on a heterogeneous group of fractures, from lowenergy splits to highly comminuted open bicondylar injuries. $^{4}$

Early complications include wound infection and deep-vein thrombosis, the rates of which are reported to be between $5 \%$ to $10 \%$. Pulmonary embolism occurs in $1 \%$ to $2 \%$ of patients. ${ }^{70,77}$ The incidence of wound infections appears to correlate with soft-tissue compromise and the amount of metal implants used. Large open surgical approaches for internal fixation add to this risk, with rates of infection reaching $80 \%{ }^{78}$ Heightened attention to the soft-tissue envelope and newer, minimally invasive techniques offer the possibility of 
Table I. Clinical and radiological outcomes listed by surgical approach

\begin{tabular}{|c|c|c|c|c|c|c|}
\hline Authors & Number of patients & $\begin{array}{l}\text { Follow-up } \\
\text { (mths) }\end{array}$ & Complications* & Radiological outcome $^{\dagger}$ & Clinical outcome $e^{\ddagger}$ & $\begin{array}{l}\text { Range of } \\
\text { movement }\left({ }^{\circ}\right)\end{array}$ \\
\hline \multicolumn{7}{|l|}{ Single approach } \\
\hline Gosling et $\mathrm{al}^{7}$ & 69 & 12 & $\begin{array}{l}\text { Deep infection (1\%), } \\
\text { superficial infection } \\
(6 \%), \mathrm{NU}(4 \%)\end{array}$ & $\begin{array}{l}\text { Anatomical reduction } \\
(78 \%) \text {, } \\
\text { Loss of reduction }(14 \%)\end{array}$ & & \\
\hline \multicolumn{7}{|l|}{ Staged protocol } \\
\hline Egol et $\mathrm{al}^{13}$ & 53 & 16 & $\begin{array}{l}\text { Deep infection }(5 \%), \\
\text { NU }(4 \%), \\
\text { Revisions (16\%) }\end{array}$ & $\begin{array}{l}100 \% \text { within } 5^{\circ} \text { of } \\
\text { anatomical reduction, } \\
\text { arthritis }(5 \%)\end{array}$ & WOMAC 91 & 1 to 106 \\
\hline \multicolumn{7}{|l|}{ Indirect reduction } \\
\hline Canadian OTS $\mathrm{S}^{\S 60}$ & 42 & $24^{\pi}$ & $\begin{array}{l}\text { Deep infection }(5 \%), \\
0 \% \text { revisions }\end{array}$ & Arthritis $(37 \%)$ & HHS 75 & 3 to 123 \\
\hline Chan et al ${ }^{16}$ & 18 & 28 & $\begin{array}{l}\text { Superficial pin } \\
\text { infection }(67 \%)\end{array}$ & $\begin{array}{l}\text { Anatomical reduction } \\
(78 \%), \text { DU }(17 \%) \\
\text { requiring revision }\end{array}$ & KSS 66 & 103 \\
\hline Koval et al ${ }^{43}$ & 18 & 16 & 0 & $\begin{array}{l}\text { Anatomical reduction } \\
(72 \%)\end{array}$ & $89 \%$ good/excellent & \\
\hline \multicolumn{7}{|l|}{ Dual approach } \\
\hline Canadian OTS ${ }^{60}$ & 40 & $24^{\pi}$ & $\begin{array}{l}\text { Deep infection }(20 \%) \text {, } \\
\text { ROH }(20 \%) \text {, revision } \\
(10 \%)\end{array}$ & Arthritis (29\%) & HHS 68 & 4 to 113 \\
\hline Marti et al ${ }^{67}$ & 109 & 168 & $\begin{array}{l}\text { Deep infection (10\%), } \\
\text { MU (7\%) }\end{array}$ & $\begin{array}{l}\text { Anatomical reduction } \\
(93 \%) \text {, moderately } \\
\text { severe arthritis }(10 \%)\end{array}$ & HHS 88.6 & 135 \\
\hline Bhattacharyya et al ${ }^{29}$ & 13 & 20 & $\begin{array}{l}\text { Superficial infection } \\
(8 \%) \\
\text { Flexion contracture } \\
(8 \%)\end{array}$ & $100 \%$ union & $100 \%$ good & 5 to 110 \\
\hline \multicolumn{7}{|l|}{ Posterior approach } \\
\hline Barei et $\mathrm{al}^{26}$ & 41 & 59 & $\begin{array}{l}\text { Deep infection }(5 \%) \text {, } \\
\text { DVT }(20 \%), \text { ROH } \\
(25 \%)\end{array}$ & $\begin{array}{l}\text { Anatomical reduction } \\
(55 \%)\end{array}$ & MFA 26.2 & \\
\hline Lobenhoffer et al ${ }^{28}$ & 29 & 48 & MU (10\%), TKR (7\%) & $80 \%$ good/excellent & $95 \%$ good/excellent & \\
\hline $\begin{array}{l}\text { De Boeck and } \\
\text { Opdecam } \\
\text { Opd }\end{array}$ & 7 & 80 & $\begin{array}{l}\text { Superficial infection } \\
(14 \%)\end{array}$ & $0 \mathrm{MU}$ & $100 \%$ good/excellent & 7 to 122 \\
\hline Georgiadis $^{85}$ & 4 & 18 & 0 & $100 \%$ good & $100 \%$ good & 2 to 125 \\
\hline \multicolumn{7}{|c|}{ * NU, nonunion; ROH, removal of hardware; MU, malunion; DVT, deep-vein thrombosis; TKR, total knee replacement } \\
\hline \multicolumn{7}{|c|}{ † DU, delayed union } \\
\hline \multicolumn{7}{|c|}{$\begin{array}{l}\text { ¥ WOMAC, Western Ontario McMasters Index (functional knee score); HHS, Harris hip score; KSS, knee society score; MFA, musculoskeletal } \\
\text { functional assessment }\end{array}$} \\
\hline \multicolumn{7}{|c|}{ § OTS, Orthopaedic Trauma Society } \\
\hline
\end{tabular}

minimising these risks, but infection still occurs in approximately $10 \%$ to $14 \%$ of high-energy injuries. ${ }^{2,79}$

Late complications include loss of fixation, redisplacement, malunion, nonunion, and post-traumatic arthritis, which may result from the initial chondral damage or may be related to residual incongruity of the joint. . $^{3,44,66,75,80}$ Avascular necrosis has occurred after combined medial and lateral plating, especially when performed through an anterior midline approach. ${ }^{81}$ Considerable rates of arthrofibrosis are reported with the use of circular ring fixators, but also pose a risk for any method of fixation in highenergy fractures. ${ }^{2,4,65,78,82}$ Schatzker et $\mathrm{al}^{3}$ found an acceptable clinical outcome of $80 \%$ only if the period of immobilisation was for less than four weeks and if the bone had no signs of osteoporosis.

A technique for the late improvement of joint congruency in malunited fractures was proposed by Marti et al. ${ }^{67}$ In patients with valgus malalignment and residual intraarticular depression an oblique osteotomy of the middle third of the fibula and an open wedge osteotomy of the tibia, combined with arthrotomy and disimpaction of joint incongruency were performed. By this technique a mean correction in the coronal plane of $9^{\circ}$ was achieved and 15 of 23 patients had no further radiological evidence of progression of osteoarthritis with a good clinical outcome at 14 years. 
As demonstrated in several studies, the rate of posttraumatic arthritis is high. The Canadian Orthopaedic Trauma Society showed that $30 \%$ of patients had radiological signs of arthritis at two years regardless of treatment. ${ }^{60}$ Vince and Abdeen ${ }^{83}$ observed wound complications in total knee replacement (TKR) after fractures of the tibial plateau, relating them to soft-tissue compromise and multiple incisions during ORIF. They recommended the use of the most lateral incision, the most recently healed incision or soft-tissue reconstruction. Saleh et $\mathrm{al}^{80}$ treated 15 patients after ORIF of fractures of the tibial plateau by TKR. They showed adequate functional outcome with the Hospital for Special Surgery outcome score increased from 51 to 80 points, but there was a high rate of complications with infection in $20 \%$ and rupture of the patellar tendon in $13 \%$.

\section{Summary}

The operative treatment of fractures of the tibial plateau is challenging. It requires a detailed history and physical examination, imaging, availability of resources and skill and determination of the best timing. Treatment algorithms should involve the type of fracture, meticulous assessment of the soft tissues and other comorbidities. A good clinical outcome with regard to function and the prevention of osteoarthritis can be achieved when the initial fixation provides anatomical reduction and secondary loss of reduction can be avoided. Newer biological techniques and the development of locked-plate technology have improved outcomes, lowered the rates of revision and lessened the occurrence of deep soft-tissue infections. However, nonunion, avascular necrosis, soft-tissue compromise and deep infection remain concerns.

\section{References}

1. Mueller ME, Allgoewer M, Schneider R, Willenegger H. Goals and basic principles of the AO-technique (Ziele, Grundlagen und Principien der A0-Technik). In: Mueller ME, Allgoewer M, Schneider R, Willenegger H, eds. Manual der osteosynthese. Vol. 1. First edition. Berlin: Springer, 1969:3-7.

2. Young MJ, Barrack RL. Complications of internal fixation of tibial plateau fractures. Orthop Rev 1994;23:149-54

3. Schatzker J, McBroom R, Bruce D. The tibial plateau fracture: the Toronto experience 1968-1975. Clin Orthop 1979;138:94-104.

4. Papagelopoulos PJ, Partsinevelos AA, Themistocleous GS, et al. Complications after tibia plateau fracture surgery. Injury 2006;37:475-84.

5. Farouk 0, Krettek C, Miclau T, et al. Minimally invasive plate osteosynthesis: does percutaneous plating disrupt femoral blood supply less than the traditional technique? J Orthop Trauma 1999;13:401-6.

6. Farouk O, Krettek C, Miclau T, Schandelmaier P, Tscherne H. Effects of percutaneous and conventional plating techniques on the blood supply to the femur. Arch Orthop Trauma Surg 1998;117:438-41.

7. Gosling T, Schandelmaier P, Muller M, et al. Single lateral locked screw plating of bicondylar tibial plateau fractures. Clin Orthop 2005;439:207-14.

8. Cole PA, Zlowodzki M, Kregor PJ. Compartment pressures after submuscular fixation of proximal tibia fractures. Injury 2003;34(Suppl 1):43-6.

9. Henry SL, Ostermann PA, Seligson D. The antibiotic bead pouch technique: the management of severe compound fractures. Clin Orthop 1993;295:54-62.

10. Gustilo RB, Anderson JT. Prevention of infection in the treatment of one thousand and twenty-five open fractures of long bones: retrospective and prospective analyses. J Bone Joint Surg [Am] 1976;58-A:453-8.

11. Tscherne $\mathbf{H}$, Oestern HJ. A new classification of soft-tissue damage in open and closed fractures (author's transI). Unfallheikunde 1982;85:111-15 (in German).
12. Roberts CS, Pape HC, Jones AL, et al. Damage control orthopaedics: evolving concepts in the treatment of patients who have sustained orthopaedic trauma. Instr Course Lect 2005;54:447-62.

13. Egol KA, Tejwani NC, Capla EL, Wolinsky PL, Koval KJ. Staged management of high-energy proximal tibia fractures (OTA types 41): the results of a prospective, standardized protocol. J Orthop Trauma 2005;19:448-55.

14. Sirkin M, Sanders R, DiPasquale T, Herscovici D Jr. A staged protocol for soft tissue management in the treatment of complex pilon fractures. J Orthop Trauma 1999;13:78-84

15. Rafii M, Firooznia H, Golimbu C, Bonamo J. Computed tomography of tibial plateau fractures. AJR Am J Roentgenol 1984;142:1181-6.

16. Chan PS, Klimkiewicz JJ, Luchetti W, et al. Impact of CT scan on treatment plan and fracture classification of tibial plateau fractures. J Orthop Trauma 1997;11:484-9.

17. Liow RY, Birdsall PD, Mucci B, Greiss ME. Spiral computed tomography with two- and three-dimensional reconstruction in the management of tibial plateau fractures. Orthopedics 1999;22:929-32.

18. Mui LW, Engelsohn E, Umans H. Comparison of CT and MRI in patients with tibial plateau fracture: can CT findings predict ligament tear or meniscal injury? Skeletal Radiol 2007;36:145-51

19. Wicky S, Blaser PF, Blanc CH, et al. Comparison between standard radiography and spiral CT with $3 \mathrm{D}$ reconstruction in the evaluation, classification and management of tibial plateau fractures. Eur Radio/ 2000;10:1227-32.

20. Khoury A, Siewerdsen JH, Whyne CM, et al. Intraoperative cone-beam CT for image-guided tibial plateau fracture reduction. Comput Aided Surg 2007;12:195-207.

21. Gardner MJ, Yacoubian S, Geller D, et al. The incidence of soft tissue injury in operative tibial plateau fractures: a magnetic resonance imaging analysis of 103 patients. J Orthop Trauma 2005;19:79-84.

22. Yacoubian SV, Nevins RT, Sallis JG, Potter HG, Lorich DG. Impact of MRI on treatment plan and fracture classification of tibial plateau fractures. J Orthop Trauma 2002;16:632-7

23. Chiba T, Sugita T, Onuma M, Kawamata T, Umehara J. Injuries to the posterolateral aspect of the knee accompanied by compression fracture of the anterior part of the medial tibial plateau. Arthroscopy 2001;17:642-7.

24. Wahlquist $\mathbf{M}$, laguilli $\mathbf{N}$, Ebraheim $\mathbf{N}$, Levine J. Medial tibial plateau fractures: a new classification system. J Trauma 2007;63:1418-21.

25. Charalambous CP, Tryfonidis M, Alvi F, et al. Inter- and intra-observer variation of the Schatzker and A0/OTA classifications of tibial plateau fractures and a proposal of a new classification system. Ann R Coll Surg Eng/ 2007;89:400-4.

26. Barei DP, Nork SE, Mills WJ, et al. Functional outcomes of severe bicondylar tibial plateau fractures treated with dual incisions and medial and lateral plates. J Bone Joint Surg [Am] 2006;88-A:1713-21.

27. Fernandez DL. Anterior approach to the knee with osteotomy of the tibial tubercule for bicondylar tibial fractures. J Bone Joint Surg [Am] 1988;70-A:208-19.

28. Lobenhoffer P, Gerich T, Bertram T, et al. Particular posteromedial and posterolateral approaches for the treatment of tibial head fractures. Unfallchirurg 1997:100:957-67 (in German).

29. Bhattacharyya T, McCarty LP 3rd, Harris MB, et al. The posterior shearing tibial plateau fracture: treatment and results via a posterior approach. J Orthop Trauma 2005; 19:305-10.

30. Jiang R, Luo CF, Wang MC, Yang TY, Zeng BF. A comparative study of Less Invasive Stabilization System (LISS) fixation and two-incision double plating for the treatment of bicondylar tibial plateau fractures. Knee 2008;15:139-43.

31. Lee JA, Papadakis SA, Moon C, Zalavras CG. Tibial plateau fractures treated with the less invasive stabilisation system. Int Orthop 2007;31:415-18.

32. Barei DP, Nork SE, Mills WJ, Henley MB, Benirschke SK. Complications associated with internal fixation of high-energy bicondylar tibial plateau fractures utilizing a two-incision technique. J Orthop Trauma 2004;18:649-57.

33. Covall DJ, Fowble CD, Foster TE, Whitelaw GP. Bicondylar tibial plateau fractures: principles of treatment. Contemp Orthop 1994;28:115-22.

34. Watson JT, Wiss DA. Tibial plateau fractures: open reduction internal fixation. In: Wiss DA, ed. Master techniques in orthopaedic surgery: fractures. Vol. 1. Second edition. Philadelphia: Lippincott Williams \& Wilkins, 2006:407-38.

35. Gossling HR, Peterson CA. A new surgical approach in the treatment of depressed lateral condylar fractures of the tibia. Clin Orthop 1979;140:96-102.

36. Moore TM. Fracture-dislocation of the knee. Clin Orthop 1981;156:128-40.

37. Tscherne H, Lobenhoffer P. Tibial plateau fractures: management and expected results. Clin Orthop 1993;292:87-100.

38. Delamarter R, Hohl M. The cast brace and tibial plateau fractures. Clin Orthop 1989;242:26-31.

39. Duwelius PJ, Connolly JF. Closed reduction of tibial plateau fractures: a comparison of functional and roentgenographic end results. Clin Orthop 1988;230:116-26.

40. Waddell JP, Johnston DW, Neidre A. Fractures of the tibial plateau: a review of ninety-five patients and comparison of treatment methods. J Trauma 1981;21:376-81. 
41. Savoie FH, Vander Griend RA, Ward EF, Hughes JL. Tibial plateau fractures: a review of operative treatment using A0 technique. Orthopedics 1987;10:745-50.

42. Charnley J. The closed treatment of common fractures. Third edition. Baltimore Williams \& Wilkins, 1961.

43. Koval KJ, Sanders R, Borrelli J, et al. Indirect reduction and percutaneous screw fixation of displaced tibial plateau fractures. J Orthop Trauma 1992;6:340-6.

44. Koval KJ, Helfet DL. Tibial plateau fractures: evaluation and treatment. J Am Acad Orthop Surg 1995;3:86-94.

45. Koval KJ, Polatsch D, Kummer FJ, Cheng D, Zuckerman JD. Split fractures of the lateral tibial plateau: evaluation of three fixation methods. J Orthop Trauma 1996;10:304-8

46. Smith WR, Ziran BH, Anglen J0, Stahel PF. Locking plates: tips and tricks. J Bone Joint Surg [Am] 2007;89-A:2298-307.

47. Stokel EA, Sadasivan KK. Tibial plateau fractures: standardized evaluation of operative results. Orthopedics 1991;14:263-70.

48. Perry CR, Evans LG, Rice S, Fogarty J, Burdge RE. A new surgical approach to fractures of the lateral tibial plateau. J Bone Joint Surg [Am] 1984;66-A:1236-40.

49. Moore TM, Patzakis MJ, Harvey JP. Tibial plateau fractures: definition, demographics, treatment rationale, and long-term results of closed traction management or operative reduction. J Orthop Trauma 1987;1:97-119.

50. Gosling T, Schandelmaier P, Marti A, et al. Less invasive stabilization of complex tibial plateau fractures: a biomechanical evaluation of a unilateral locked screw plate and double plating. J Orthop Trauma 2004;18:546-51.

51. Karunakar MA, Egol KA, Peindl R, et al. Split depression tibial plateau fractures a biomechanical study. J Orthop Trauma 2002;16:172-7.

52. Mueller KL, Karunakar MA, Frankenburg EP, Scott DS. Bicondylar tibial plateau fractures: a biomechanical study. Clin Orthop 2003:412:189-95.

53. Higgins TF, Klatt J, Bachus KN. Biomechanical analysis of bicondylar tibial plateau fixation: how does lateral locking plate fixation compare to dual plate fixation? Orthop Trauma 2007;21:301-6.

54. Belanger M, Fadale P. Compartment syndrome of the leg after arthroscopic examination of a tibial plateau fracture: case report and review of the literature. Arthros copy 1997;13:646-51

55. Lubowitz JH, Elson WS, Guttmann D. Part I: arthroscopic management of tibia plateau fractures. Arthroscopy 2004;20:1063-70.

56. Lubowitz JH, Elson WS, Guttmann D. Part II: arthroscopic treatment of tibial plateau fractures: intercondylar eminence avulsion fractures. Arthroscopy 2005;21:86-

57. Lobenhoffer P, Schulze M, Gerich T, Lattermann C, Tscherne H. Closed reduction/percutaneous fixation of tibial plateau fractures: arthroscopic versus fluoroscopic control of reduction. J Orthop Trauma 1999;13:426-31.

58. Reid JS, Van Slyke MA, Moulton MJ, Mann TA. Safe placement of proximal tibial transfixation wires with respect to intracapsular penetration. J Orthop Trauma 2001;15:10-17

59. Watson JT. High-energy fractures of the tibial plateau. Orthop Clin North Am 1994:25:723-52.

60. No authors listed. Canadian Orthopaedic Trauma Society: open reduction and internal fixation compared with circular fixator application for bicondylar tibial plateau fractures: results of a multicenter, prospective, randomized clinical trial. J Bone Joint Surg [Am] 2006;88-A:2613-23.

61. Mahadeva D, Costa ML, Gaffey A. Open reduction and internal fixation versus hybrid fixation for bicondylar/severe tibial plateau fractures: a systematic review of the literature. Arch Orthop Trauma Surg 2008;128:1169-75

62. Kumar A, Whittle AP. Treatment of complex (Schatzker Type VI) fractures of the tibial plateau with circular wire external fixation: retrospective case review. J Orthop Trauma 2000:14:339-44.
63. Mikulak SA, Gold SM, Zinar DM. Small wire external fixation of high energy tibial plateau fractures. Clin Orthop 1998;356:230-8.

64. Berkson EM, Virkus WW. High-energy plateau fractures. J Am Acad Orthop Surg 2006;14:20-31.

65. Ali AM, Burton M, Hashmi M, Saleh M. Outcome of complex fractures of the tibial plateau treated with a beam-loading ring fixation system. J Bone Joint Surg [Br] 2003;85-B:691-9.

66. Weigel DP, Marsh JL. High-energy fractures of the tibial plateau: knee function after longer follow-up. J Bone Joint Surg [Am] 2002;84-A:1541-51.

67. Marti RK, Kerkhoffs GM, Rademakers MV. Correction of lateral tibial plateau depression and valgus malunion of the proximal tibia. Oper Orthop Traumatol 2007;19:101-13.

68. Lucht U, Pilgaard S. Fractures of the tibial condyles. Acta Orthop Scand 1971;42:366-76.

69. Rasmussen PS. Tibial condylar fractures: impairment of knee joint stability as an indication for surgical treatment. J Bone Joint Surg [Am] 1973;55-A:1331-50.

70. Blokker CP, Rorabeck CH, Bourne RB. Tibial plateau fractures: an analysis of the results of treatment in 60 patients. Clin Orthop 1984;182:193-9.

71. Keating JF, Hajducka CL, Harper J. Minimal internal fixation and calciumphosphate cement in the treatment of fractures of the tibial plateau: a pilot study. $J$ Bone Joint Surg [Br] 2003;85-B:68-73.

72. Trenholm A, Landry S, McLaughlin K, et al. Comparative fixation of tibial plateau fractures using alpha-BSM, a calcium phosphate cement, versus cancellous bone graft. J Orthop Trauma 2005;19:698-702.

73. Welch RD, Zhang H, Bronson DG. Experimental tibial plateau fractures augmented with calcium phosphate cement or autologous bone graft. J Bone Joint Surg [Am] 2003;85-A:222-31.

74. Stevens DG, Beharry R, McKee MD, Waddell JP, Schemitsch EH. The longterm functional outcome of operatively treated tibial plateau fractures. J Orthop Trauma 2001;15:312-20.

75. Honkonen SE. Degenerative arthritis after tibial plateau fractures. J Orthop Trauma 1995:9:273-7.

76. Jensen DB, Rude C, Duus B, Bjerg-Nielsen A. Tibial plateau fractures: a comparison of conservative and surgical treatment. J Bone Joint Surg [Br] 1990;72-B:49-52.

77. Lachiewicz PF, Funcik T. Factors influencing the results of open reduction and internal fixation of tibial plateau fractures. Clin Orthop 1990;259:210-15.

78. Dendrinos GK, Kontos S, Katsenis D, Dalas A. Treatment of high-energy tibial plateau fractures by the llizarov circular fixator. J Bone Joint Surg [Br]1996;78-B:710-

79. Stannard JP, Wilson TC, Volgas DA, Alonso JE. Fracture stabilization of proximal tibial fractures with the proximal tibial LISS: early experience in Birmingham, Alabama (USA). Injury 2003;34(Suppl 1):36-42.

80. Saleh KJ, Sherman P, Katkin P, et al. Total knee arthroplasty after open reduction and internal fixation of fractures of the tibial plateau: a minimum five-year follow-up study. J Bone Joint Surg [Am] 2001;83-A:1144-8.

81. Tejwani NC, Hak DJ, Finkemeier CG, Wolinsky PR. High-energy proximal tibial fractures: treatment options and decision making. Instr Course Lect 2006;55:367-79.

82. Gausewitz S, Hohl $\mathbf{M}$. The significance of early motion in the treatment of tibial plateau fractures. Clin Orthop 1986;202:135-8.

83. Vince KG, Abdeen A. Wound problems in total knee arthroplasty. Clin Orthop 2006; $452: 88-90$

84. De Boeck H, Opdecam P. Posteromedial tibial plateau fractures: operative treatment by posterior approach. Clin Orthop 1995;320;125-8.

85. Georgiadis GM. Combined anterior and posterior approaches for complex tibial plateau fractures. J Bone Joint Surg [Br] 1994;76-B:285-9. 